\title{
Accurate Prediction Model of Financial Early-warning for Listed Companies Based on Logistics Regression Analysis
}

\author{
Yang Suqin ${ }^{1, ~ a}$, Li Yue $^{2, b}$ \\ ${ }^{1}$ Guangzhou Huali Science and Technology Vocational College, Guangzhou511300, China. \\ ${ }^{2}$ Guangzhou Huashang Vocational College, Guangzhou511300, China. \\ ysq19850119@163.com, b15989280129@126.com
}

Keywords: logistics regression analysis; listed company; financial early-warning; accounting

Abstract: To improve the ability of financial early-warning and accounting statistical analysis of listed companies, an accurate forecasting model of financial early warning for listed companies based on logistics regression analysis was proposed. The explanatory variable model and control variable model of financial early-warning of listed company are constructed, the information flow of financial management data of listed company is set up, and the characteristic quantity of financial early-warning of listed company is analyzed by descriptive statistical analysis method. This paper recombines the sample data of listed companies with nonlinear characteristics, and the panel data matching method is used to test and analyze the financial warning data of listed companies by linear piecewise sample. The logistics regression analysis method is used to realize the financial early-warning and accurate forecast of listed companies. The experimental results show that the model is accurate and robust.

\section{Introduction}

With the sustainable development of economy, the emergence of new business and the increasing number of derivative financial products, the traditional accounting has been greatly impacted, and the financial risks of listed companies are gradually increasing. The single measurement view cannot reflect the complex economic affairs of the enterprise objectively and realistically. The current accounting standards for enterprises clearly point out that the accounting of our country can use the following five measuring attributes: historical cost, replacement cost, net realizable value, present value and fair value. The reason why the accounting measurement attribute is important is that it is the quantitative reflection of the accounting elements, which determines the size of the amount in the accounting, and thus will have a decisive impact on the final financial situation, operating results and cash flow of the enterprise. However, the above accounting measurement attributes cannot effectively reflect the financial situation of listed companies ${ }^{[1]}$. It has great significance to improve the financial monitoring ability of listed companies and to study the financial early-warning model of listed companies. 
The financial early-warning forecasting model of listed companies can help outside information users to understand the business situation effectively and help to maintain social and economic stability. Although many literatures define financial distress as "long-term serious cash flow problem", in the empirical research, "bankruptcy" is usually taken as the sign of financial distress ("failure" is defined as "failure" as the company can not pay due debt. From an operational point of view, the company can fail as long as one of the following events occurs: bankruptcy, bond default, overdraft bank account or refusal to pay preferred stock dividends. Mears (1968) has misgivings about the last three situations that constitute an operational failure. Because default can be corrected, overdraft problems in bank accounts can be handled properly, and preferred stock dividends can be recalculated, these three situations are not necessarily associated with failure ${ }^{[2]}$. In order to avoid the concept defect of dividing financial distress into failure and non-failure companies, this paper defines financial distress by bankruptcy criterion, neglecting the actual situation of enterprise: even if a company is facing long-term cash flow problems, it also has many alternatives to bankruptcy. Such as divestiture or sale of shares, redefining business objectives or reducing the size of the business, or selling off all assets to make a profit, or seeking a merger partner. This paper presents an accurate financial forecasting model of listed companies based on Logistics regression analysis. The financial early-warning data of the sampled listed companies is combined to realize the optimization of the financial early-warning prediction. Finally, the experimental analysis is carried out, and the effective conclusion is drawn.

\section{Analysis of financial early warning characteristic data and variable analysis of listed companies}

\subsection{Construction of financial early-warning characteristic data model of listed companies}

In order to optimize the design of financial model and improve the intelligent level of financial management, big data analysis method is used to test and analyze financial data. The financial early-warning data model of listed companies is constructed by combining robustness test and stochastic prediction, and the financial monitoring feature data prediction of listed companies is carried out based on time-frequency joint distribution feature extraction method. The method of descriptive statistical analysis is used to sample the original financial $\operatorname{data}^{[3]}$. The sample of financial data comes from about 150 enterprises in a certain province. The time period of collecting financial management data is from 2013 to 2017, and 2000 groups of sample data are collected. According to the characteristic distribution of financial data and the composition of capital structure, the statistical characteristic model of financial data is constructed by means of random sampling and quantitative analysis, and the statistical evaluation decision function of financial model is obtained as:

$$
x_{n}=a_{0}+\sum_{i=1}^{M_{A R}} a_{i} x_{n-i}+\sum_{j=0}^{M_{M A}} b_{j} \eta_{n-j}
$$

Where, the decision variable function contains $N$ fictitious samples of debt financing, in which the enterprise financing risk internal control sample $x_{i}, i=1,2, \cdots, n$, and the decision feedback equalization method are used for the descriptive sample iteration of the financial data, and the grouping iteration model is obtained as: 


$$
\left\{\begin{array}{l}
\min \sum_{1 \leq i \leq K} \sum_{e \subseteq k(e)} \frac{f(e(i))}{C(e, i)} \\
0 \leq f(e, i) \leq C(e, i) \\
F=\text { const } \\
\sum_{1 \leq i \leq K, e \subseteq k(e)} \frac{f(e(i))}{C(e, i)}+\sum_{e \subseteq k(e)} \frac{f\left(e^{\prime}(i)\right)}{C\left(e^{\prime}, i\right)} \leq k(v)
\end{array}\right.
$$

Based on the method of financial number sampling endogenous financing control, the statistical analysis results of financial monitoring characteristic data of listed companies are given in section $n$. Big data information fusion in financial model is carried out by using high-dimensional feature vector fusion method ${ }^{[4]}$. The distribution distance of financial monitoring feature data of listed companies in high-dimensional phase space clustering center is obtained as follows:

$$
d_{0}=\sqrt[n_{0}]{\frac{\alpha_{1}+\beta}{\left(n_{0}-1\right) \alpha_{2}}}
$$

Where, $n_{0}$ is the distributed cross item coefficient of financial monitoring feature data of listed companies, $\beta$ is the capital attribute set of enterprise operation. The characteristic data of financial monitoring of listed companies form a smooth rule feature attribute set in the dimension phase space. The expression of probability density function for accurate prediction of financial monitoring feature data of listed companies is expressed as follows:

$$
p(U \mid \Theta)=\sum_{k=1}^{K} \alpha_{k} G\left(U \mid u_{k}, \sum_{k}\right)
$$

Where, $G\left(U \mid \mu_{k}, \sum_{k}\right)$ is the internal control constraint parameter of the financial model. Under big data environment, the descriptive statistical analysis and linear regression analysis of the financial model are carried out. According to the results of the statistical analysis, the feature extraction and information fusion processing are carried out ${ }^{[5]}$.

\subsection{Analysis of financial early warming control variables and explanatory variables}

The cash flow (NWCFF) of the net working capital is replaced by 5 items such as inventory, accounts receivable and accounts payable, and 12 cash flow ratio predictors are obtained, and the explanatory variable model and the control variable model of financial early warning of listed companies are constructed ${ }^{[6]}$. The information flow of financial management data of listed companies and the structural formula of reorganizing the characteristics of financial warning data of listed companies are constructed as:

$$
C W_{\min }^{l_{M}}=C W_{\min }^{l_{M-1}} \times\left(1+\bar{D}_{l_{M-1}}\right)^{\chi}=C W_{\min }^{0} \times\left(1+\bar{D}_{l_{0}}\right)^{\chi} \times\left(1+\bar{D}_{l_{1}}\right)^{\chi} \times \cdots \times\left(1+\bar{D}_{l_{M-1}}\right)^{\chi}=C W_{\min }^{0} \times\left[\left(1+\bar{D}_{l_{0}}\right) \times\left(1+\bar{D}_{l_{1}}\right) \times \cdots \times\left(1+\bar{D}_{l_{M-1}}\right)\right]^{\chi}
$$

The time scalar sequence of the time series of the financial monitoring feature data of listed companies is obtained by using the method of grouping sample test. The feature vector of the $\left\{x\left(t_{0}+i \Delta t\right)\right\}$ sampling sequence is used to reconstruct the financial early-warning data of listed companies with high-dimensional spatial mapping:

$$
X=K\left[s_{1}, s_{2}, \cdots s_{K}\right]_{\mathbf{n}}=K\left(x_{n}, x_{n-\tau}, \cdots, x_{n-(m-1) \tau}\right)
$$

Where, $K=N-(m-1) \tau$ indicates that the embedded dimension of the listed company's financial 
monitoring feature data sequence in the high-dimensional mapping is time delay ${ }^{[7]}$. Combined with adaptive iteration, under the internal incentive, the solution formula of the disclosures mutual information amount in the financial reporting form is obtained as:

$$
I(i)=\sum_{j \in \operatorname{Inf}(i) \text { 且 } j \neq i} T(j)
$$

Where, Intf $(i)=B-\frac{L \mu(i)}{128512}$, combined with subsample adaptive adjustment method, the confidence function of cash flow level of financial data is obtained. Considering the variability of $\mathrm{K}$ value, the method of grouping sample test is used for statistical analysis of financial data.

\section{Optimization of accurate prediction model for financial early warning}

On the basis of nonlinear feature recombination and high-dimensional mapping reconstruction of the sampled financial early-warning data of listed companies, the financial model is constructed, and the financial monitoring feature data prediction of listed companies is constructed in the statistical phase space. The $s_{i}=\left(x_{i}, x_{i+\tau}, \cdots, x_{i+(m-1) \tau}\right)^{T}$ obtained by the model is called the high order cumulant of the characteristic data of financial monitoring of listed companies ${ }^{[8]}$. By adopting the method of capital structure adjustment of free cash flow, the iterative formula of statistical regression analysis of financial early-warning data of listed companies is obtained as:

$$
V V^{T}=I_{M}
$$

This paper recombines the sampled financial early-warning data of listed companies with nonlinear features, and combines the panel data matching method to test and analyze the financial early-warning data of listed companies in linear piecewise samples. At this time, the financial monitoring features of listed companies are analyzed. The probability density characteristics of the capital structure validity distribution in the data are expressed as follows:

$$
R_{1}=\left\{X_{1}, X_{2}, X_{3}, \cdots, X_{d}\right\}^{T}
$$

The average mutual information feature analysis algorithm is used, the correlation function of financial monitoring feature data prediction of listed companies is obtained as follows:

$$
R_{1}^{T} R_{1}=\left\{X_{1}, X_{2}, \cdots, X_{m}\right\}\left\{X_{1}, X_{2}, \cdots, X_{m}\right\}^{T}
$$

The cash flow (NWCFF) of the net working capital is replaced by five items such as inventory, accounts receivable and accounts payable, and independent variables are selected in the multivariate model to obtain the prediction formula of the characteristic data of financial monitoring of listed companies:

$$
R_{2}^{T} R_{2}=V_{2} \sum_{2} V_{2}^{T}
$$

In the formula, the wide-area feature solution vector of financial monitoring feature data of listed companies is expressed as follows:

$$
V=\left[V_{1}, V_{2}, \cdots, V_{m}\right] \in R^{m \times m}
$$

Combined with Logistics regression analysis model, the fixed benefit analysis in financial management is carried out, and the iterative formula of regression analysis for grouping adjustment is obtained as follows:

$$
x_{1}+x_{2}+\cdots+x_{m+1}=T+t-m \times t
$$


Combining with the result of statistical analysis of difference, this paper replaces the new sequence of financial monitoring characteristic data of the original listed company. According to the above statistical analysis results, the higher-order cumulants reflecting the distribution of financial management features are extracted, and the extracted $R^{T} R$ is listed public. Division financial monitoring feature data segmented detection of eigenvalues, extracted financial data sample sequence of high-order cumulant eigenvalues of the size of the relationship is:

$$
\sigma_{1}>\sigma_{2}>\sigma_{3}>\cdots>\sigma_{s+1}>\sigma_{m}
$$

According to the results of linear regression analysis and feature extraction of higher-order cumulants, the statistical analysis and accurate prediction of financial early warning of listed companies are realized.

\section{Experimental analysis}

The application performance of this model in the realization of financial early warning prediction of listed companies is test, the empirical data are analyzed. In the case of two groups of prior samples, the linear multivariate discriminant analysis (LMDA) generates a linear discriminant function. The linear discriminant function represent entities from two different groups. By this linear discriminant function, all the p-dimensional spatial observations are simplified to one-dimensional spatial observations, and the two sets of points on the linear discriminant function are separated to the maximum extent. This discriminant function converts a set of variables of the sample into a single discriminant value ( $Z$ value), which can be used to determine which category the sample belongs to. The priori probabilities of bankrupt and non-bankrupt companies were considered (q1=10.02 for bankruptcy group, and q2=0.98 for non-bankrupt group). The misjudgment cost (C1) of the first kind of error was determined by using the loan function of commercial bank as the analytical framework, with the return of risk-free assets. According to the above empirical analysis model, the financial early warning forecast of listed companies is carried out, and the distribution of financial statistics data is shown in figure 1.

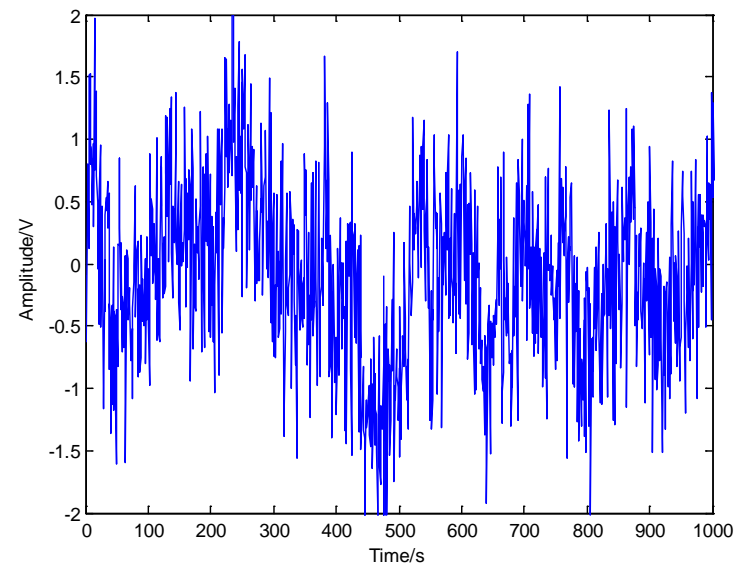

Figure 1. Financial statistics model of listed companies

Taking the financial data of figure 1 as the research object, this paper selects the econometric method of logit regression, and simplifies the problem to the fact that a company has some properties (presented by financial ratio index). The statistical analysis results of financial early warning are shown in Table 1.

Calculate the conditional probability of financial distress over a period of time, test the accuracy of different methods for financial early warning, and get the results shown in figure 2.

Figure 2 shows that the method of this paper has high accuracy and confidence level. 
Table 1. Results of financial early warning statistical analysis of listed companies

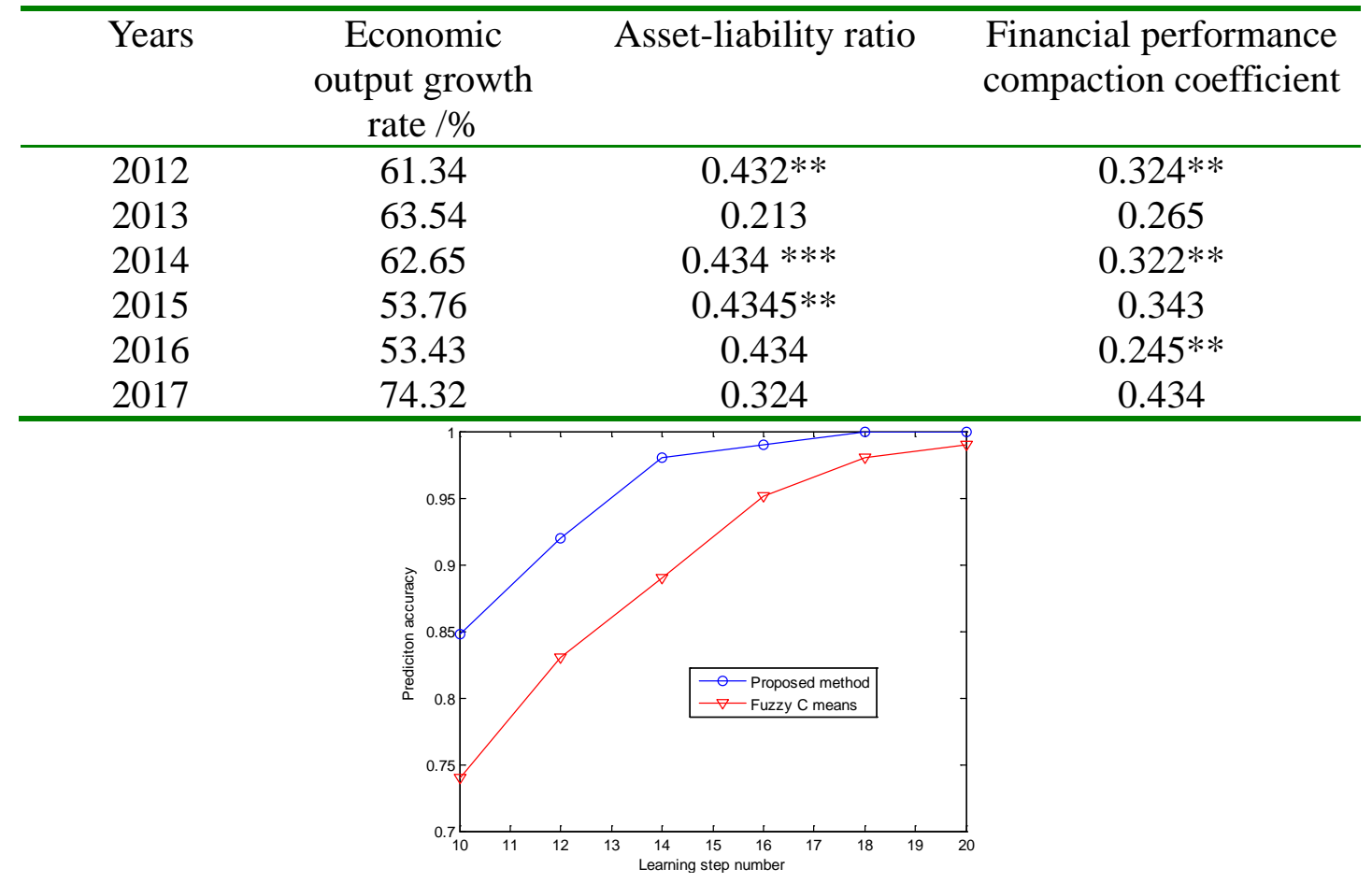

Figure 2. Comparison of accuracy of financial early warning

\section{Conclusions}

In this paper, an accurate financial forecasting model of listed companies based on Logistics regression analysis is proposed. The explanatory variable model and control variable model of financial early warning of listed company are constructed, and the information flow of financial management data of listed company is established. The statistical analysis of characteristic quantity of financial early warning of city company is carried out by using descriptive statistical analysis method. The sampled financial early-warning data of listed companies are reorganized with nonlinear characteristics, and the linear piecewise sample test and analysis of financial early-warning data of listed companies are carried out with panel data matching method, and the method of Logistics regression analysis is used to realize the listing of listed companies. The company financial early warning accurate forecast. The experimental results show that the model is accurate and robust.

\section{References}

[1] Min Bai,Yafeng Qin. Short-sales Constraints and Liquidity Change: Cross-sectional Evidence from the Hong Kong Market[J]. Pacific-Basin Finance Journal,2014,26: 98-122.

[2] Marcel,F. Capital Flows Push versus Pull Factors and the Global Financial Crisis[J]. Journal of International Economics,2011,88(2): 341-356

[3] Taguchi,H.,Sahoo,P., Nataraj,G. Capital Flows and Asset Prices: Empirical Evidence from Emerging and Developing Economies[J]. International Economics,2015,141(5): 1-14

[4] PAN Jizheng. Improvement of accounting method of large scientific research project based on Evolutionary Game Theory[J]. Management Engineer, 2017,22(1):36-40.

[5] YAO Lei, YAO Wang Xin. Research on the policy effect of incremental expansion of margin and securities lending: Based on the multi period DID model and Hausman's test [J]. international financial research, 2016, 349 (5): 85-96.

[6] GUO Huaping, ZHOU Jun, WU Chang'an, FAN Ming. k-nearest neighbor classification method for 
class-imbalanced problem. Journal of Computer Applications, 2018, 38(4): 955-959.

[7] Ye M, Qian Y, Zhou J. Multitask sparse nonnegative matrix factorization for joint spectral-spatil hyperspectral imagery denoising[J]. IEEE Transactions on Geoscience and Remote Sensing, 2015, 53(5):2621-2639.

[8] Hu L R, Wu J G, Wang L. Application and method for linear projective non-negative matrix factorization[J]. Computer Science, 2013, 40(10):269-273. 